\title{
Estándares de la Corte Interamericana de Derechos Humanos en materia de imputados y condenados privados de libertad
}

\author{
The jurisprudence standards of the Inter-American Court of Human Rights \\ about accused and sentenced prisoners
}

\author{
Álvaro Castro Morales \\ Universidad de Chile
}

\begin{abstract}
RESUMEN Este artículo analiza los estándares jurisprudenciales de la Corte Interamericana de Derechos Humanos en materia de imputados y condenados privados de libertad. Se describe el rol de la Corte en cuanto mecanismo internacional de protección de derechos de los privados de libertad, el contexto político criminal y realidad de las prisiones latinoamericanas, los derechos que comúnmente han sido violados en las prisiones y lugares de detención, y las líneas jurisprudenciales más relevantes sobre el tema en cuestión.
\end{abstract}

PALABRAS CLAVE Privados de libertad, vulneración de derechos, estándares jurisprudenciales, Corte Interamericana de Derechos Humanos.

ABSTRACT This article analyzes the jurisprudential standards of the Inter-American Court of Human Rights about accused and sentenced prisoners. The article describes the role of the Court as an international mechanism for the protection of the rights of prisoners, the criminal political context and the reality of Latin American prisons, the rights that have commonly been violated in prisons and places of detention, and the most relevant jurisprudential lines on the subject.

KEYWORDS Prisoners, violation of rights, jurisprudential standards, Inter-American Court of Human Rights. 


\section{Rol de la Corte como mecanismo internacional de control de derecho de los privados de libertad}

El derecho internacional desconfía de toda forma de privación de libertad. ${ }^{1}$ La posibilidad de que se generen abusos en un cuartel policial o una cárcel es elevada. ${ }^{2}$ La importancia de que se exijan mecanismos de control que revisen el ingreso, las condiciones materiales y las decisiones de los agentes del Estado encargados de la ejecución de la sanción penal es en extremo relevante (Medina, 2003).

Para estos efectos, la doctrina recomienda el funcionamiento conjunto de mecanismos de protección de derechos que posean diversa naturaleza, sean integrados por diferentes actores y organizados tanto dentro como fuera del país. Se habla en la literatura de controles nacionales, internacionales, políticos, administrativos, comunitarios y judiciales. También, de mecanismos de control que se abocan a la adjudicación de derechos de los presos y a escrutar las condiciones materiales en que se ejecuta la pena privativa de libertad (Koeppel, 1999).

Son ejemplo de controles internacionales el Tribunal Europeo de Derechos Humanos y la Corte Interamericana de Derechos Humanos. Pueden considerarse ejemplos de controles nacionales las comisiones parlamentarias (control político), las instancias de reclamo y solicitud de peticiones dentro de la cárcel (control administrativo o interno), las comisiones de visita o inspecciones (órganos comunitarios) y a la figura del juez de ejecución como una instancia de control judicial (Koeppel, 1999).

El trabajo de la Corte Interamericana de Derechos Humanos se enmarca dentro del control internacional, esto es, como tribunal abocado a la defensa y protección de los derechos humanos de las personas que habitan en los veinte Estados americanos que han reconocido su jurisdicción. ${ }^{3}$ En términos generales, la Corte despliega una protección complementaria y supletoria de los tribunales nacionales, es decir, interviene cuando se han agotado todos los mecanismos internos que establece un país para hacer efectiva la protección de los derechos humanos. Sus funciones radican en

1. Por libertad se entenderá el concepto desarrollado por los «Principios y buenas prácticas sobre la protección de las personas privadas de libertad en las Américas» de la Organización de los Estados Americanos. En su disposición general, se alude a toda forma de detención, encarcelamiento, institucionalización o custodio de una persona por razones de asistencia humanitaria, tratamiento, tutela, protección, o por delitos en infracciones a la ley, ordenada por o bajo el control de facto de una autoridad judicial o administrativa o cualquier otra autoridad, ya sea en una institución pública o privada, en el cual no pueda disponer de su libertad ambulatoria.

2. Véase la sentencia del caso «Niños de la calle» (Villagrán Morales y otros) con Guatemala, Corte Interamericana de Derechos Humanos, 26 de mayo de 2001, serie c número 77.

3. Los Estados que han ratificado la Convención Americana de Derechos Humanos y han aceptado la jurisdicción de la Corte son: Argentina, Barbados, Bolivia, Brasil, Colombia, Costa Rica, Chile, Ecuador, El Salvador, Guatemala, Haití, Honduras, México, Nicaragua, Panamá, Paraguay, Perú, República Dominicana, Surinam y Uruguay. 
conocer y resolver violaciones de derechos fundamentales en casos concretos, supervisar su cumplimiento, dictar medidas provisionales y ejercer una función consultiva (Steiner y Uribe, 2013: 6).

La Corte, en conjunto con la Comisión Interamericana de Derechos Humanos, ha abordado la problemática de los privados de libertad en la región y su relación con los derechos humanos a través del estudio de peticiones, casos, medidas cautelares y la adopción de informes temáticos sobre la situación carcelaria en los Estados miembros de la Organización de los Estados Americanos (CIDH, 2011a: 14). La información recibida durante sus más de cincuenta años ha permitido a estos organismos construir un verdadero corpus juris del privado de libertad (CIDH, 2011a: 14; Nash Rojas y Núñez, 2016).

\section{Contexto político criminal y situación general de las prisiones en la región}

Los casos vinculados a las vulneraciones de derechos humanos de los privados de libertad se originan bajo el periodo de los Gobiernos autoritarios o dictaduras militares, generalmente asociados a persecuciones políticas, condenas arbitrarias y encierro de presos políticos o catalogados de terroristas en recintos penitenciarios que funcionaban bajo condiciones infrahumanas y con regímenes de máxima seguridad.

Posteriormente, las vulneraciones de derechos humanos en el interior de las prisiones cambiaron de lógica y adquirieron, bajo el periodo de Gobiernos democráticos, características diferentes vinculadas con las mayores demandas de la ciudadanía en materia de seguridad pública y a las consecuentes reformas penales que los Estados han emprendido para satisfacer dichas demandas (Sozzo, 2016). No debe olvidarse que América Latina ha experimentado en las últimas dos décadas una ola de reformas a sus sistemas de justicia penal. Dichas reformas han buscado no solo reemplazar el sistema de enjuiciamiento criminal de tipo inquisitivo por uno de corte adversarial, sino también modernizar el sistema penal juvenil adecuando su normativa a la Convención de los Derechos del Niño. Con distintos niveles de intensidad y éxito, no resulta del todo inadecuado sugerir que este movimiento de reforma en la región se ha ordenado para asegurar mejoras en la efectividad de la sanción penal y, al mismo tiempo, fortalecer el respeto de las garantías de imputados y procesados (Duce, 2005; García-Méndez y Beloff, 1998; Gutbrodt, 2010; Langer, 2007).

El problema de las reformas al sistema penal de adultos y adolescentes emprendidas en los últimos años por los Estados latinoamericanos se centra en que estos cambios han dejado casi intactos los principales vicios de los sistemas penitenciarios de la región y han incrementado al máximo su carga de trabajo, lo cual ha generado un deterioro aún mayor (Dammert y Zúñiga, 2008). El aumento sostenido de la población penitenciaria en los últimos veinte años, las elevadas tasas de privados de libertad que presentan los países del continente, y los exacerbados niveles de hacina- 
miento dan cuenta de la fragilidad con que funcionan las cárceles de la región, lo que pone en jaque diariamente la dignidad humana de miles de personas que han sido condenadas a la pena privativa de libertad o sujetas a prisión preventiva. Esta fragilidad en la que vive el sistema carcelario latinoamericano tendría su explicación en la omisión histórica de los Estados en la materia y en su excesiva utilización del recurso cárcel en su lucha contra la delincuencia (CIDH, 2011a: 2).

La omisión histórica podría explicarse por la particular forma en que se ha desplegado el proceso de civilización llevado a cabo por el sistema penal. Como explica Garland (1990), la erradicación de las penas corporales significó institucionalizar el castigo, desplazarlo a esferas «privadas», darle una infraestructura propia y cuerpo administrativo que se lo apropió. La creación de la institución penitenciaria trajo una esperanza engañosa en torno a la dosificación del dolor: se pensó que sus rutinas y prácticas eliminarían la barbarie de la ejecución en medio de la plaza pública, pero no fue así. La ejecución de la pena se lleva a cabo detrás del escenario de lo público, tras bambalinas, lejos del control ciudadano y de la preocupación de las autoridades (Pratt, 2006).

La excesiva utilización del recurso cárcel tiene que ver con las estrategias que los Estados en América Latina han diseñado para hacer frente a la crisis de inseguridad ciudadana relacionada con la delincuencia patrimonial, sexual y vinculada a drogas. Las estrategias desarrolladas en la región manifiestan una excesiva confianza en el sistema penal y parten de la base de que la crisis de seguridad ciudadana se debe al insuficiente rigor de la sanción penal. Pareciera que en la región se cree que la única forma de lograr el éxito en la persecución del delito consiste en aumentar la cantidad de personas encarceladas y construir más cárceles, siguiendo el modelo de lo que en la literatura comparada se ha denominado «complejo industrial penitenciario» $(\mathrm{Cu}-$ neo, 2017: 125). De ahí que el foco de dichas reformas, en el caso de la criminalidad adulta, busque el aumento de la duración de las penas, limitar al juez a la hora de determinar la sanción penal, facilitar la aplicación de la prisión preventiva y extender su duración, restringir la aplicación de las alternativas a la pena privativa de libertad, limitar los beneficios de los presos y rigidizar aún más los regímenes penitenciarios. En el caso de los adolescentes infractores, la principal estrategia ha girado en torno a bajar la edad de imputabilidad penal para que puedan ingresar al sistema penal juvenil a una edad más temprana (CIDH, 2011b; Dammert y Arias, 2007). ${ }^{4}$

Como muestran las estadísticas del International Center for Prison Studies de King's College de Londres, ${ }^{5}$ la población penitenciaria en América Latina ha aumen-

\footnotetext{
4. Corte Internacional de Derechos Humanos, «Informe sobre seguridad ciudadana y derechos humanos», OEA/Ser.L/V/II, 31 de diciembre de 2009, disponible en http://bit.ly/2AtGQfD.

5. «World prison brief data: South America», sitio web del International Center for Prison Studies, disponible en http://bit.ly/2SgNbS7.
} 
tado explosivamente en los últimos 25 años. Al examinar el crecimiento anual de la población privada de libertad en Argentina, Bolivia, Chile, Ecuador y Panamá, las cifras demuestran que desde 1998 la población penitenciaria se ha más que duplicado, mientras que en Perú, Colombia, Costa Rica y Paraguay se ha triplicado. En Brasil, la población recluida en centros penitenciarios se ha más que cuadruplicado.

La doctrina distingue, en cuanto a tasas de privados de libertad por 100.000 habitantes, países con baja tasa (hasta 100 por 100.000 habitantes), moderada (entre 100 a 150) y extrema (superior a 150). Siguiendo esta clasificación, debemos constatar que, a diferencia de Europa, ningún país del hemisferio tiene una tasa baja y la mayoría tiene una tasa extrema. En el extremo inferior se encuentra Bolivia, con una tasa de 130. Paraguay con 158, Ecuador con 162, Venezuela con 166, Argentina con 174, Colombia con 235, Chile con 242, Perú con 252, Uruguay con 306, Brasil con 313, Costa Rica con 370 y Panamá con 421 forman parte de los países con una tasa de privados de libertad extrema.

El aumento explosivo de la población privada de libertad en la región no siempre ha ido de la mano de más inversión en infraestructura carcelaria que permita albergar de forma digna a todos los imputados y condenados a la cárcel (CIDH, 2011a: 168). La doctrina indica que la situación ideal consiste en que el número de presos no supere la capacidad máxima del centro carcelario; incluso, si llegara a existir sobreocupación en los recintos, no deberían superar el 115\% (Dünkel y otros, 2010). La falta de espacios puede generar una serie de problemas en el interior de las prisiones vinculadas con la higiene, violencia, falta de protección, aumento de la subcultura carcelaria y disminución de la calidad de los servicios, entre otros (CIDH, 2011a: 175).

De acuerdo con las estadísticas del International Center for Prison Studies, todos los países de la región exceden la capacidad máxima de plazas originalmente establecidas en sus respectivos sistemas penitenciarios. Forman parte de los países que tienen una tasa moderada de hacinamiento Argentina (112\%), Chile (115\%), ${ }^{6}$ Panamá (113\%) y Ecuador (114\%). Les siguen Costa Rica (139\%), Colombia (145\%), Venezuela (153\%), Brasil (172\%) y Paraguay (178\%). Finalmente, es posible encontrar en Bolivia y Perú porcentajes de hacinamiento superiores al $200 \%$.

El escenario latinoamericano en materia de privados de libertad difiere bastante de la realidad europea. Las tasas en 2017 varían en este continente entre 45 por

6. Si bien en Chile el porcentaje general de sobrepoblación en el país a 2016 era del 105,7\%, cifra que como se explicó se mantiene dentro de los rangos tolerados a nivel internacional, hay regiones que presentan niveles extremos de hacinamiento, lo que se traduce en recintos penitenciarios sobrepasados en sus capacidades. El Centro de Detención Preventiva Santiago Sur presenta una tasa de hacinamiento del 202,4\%; el de Talagante, de 251,5\%; el de Yungay, de 224,2\%; el de Limache, un impactante $316 \%$; el Centro de Cumplimiento Penitenciario de Curicó, de 201,1\%, y el Centro Penitenciario Femenino de Talca, de 230,6\%. Gendarmería de Chile, «Chile: Situación carcelaria en cifras», Boletín Estadístico 1, noviembre de 2016, disponible en https://bit.ly/2JKrDto. 
100.000 habitantes en Islandia y 443 en Rusia. Alemania, con una tasa de 80, forma parte del amplio grupo de países con bajas tasas de privados de libertad por 100.000 habitantes, junto con Finlandia (55), Suecia (53), Noruega (74), Dinamarca (58), Irlanda del Norte (80), Eslovenia (63), Italia (86) y Bosnia (73).

En lo que se refiere a porcentajes de hacinamiento, también pueden encontrarse en Europa marcadas diferencias con nuestra región: en términos generales, la gran mayoría de las cárceles en el continente funcionan por debajo de su máxima capacidad y los casos extremos de sobreocupación no superan el 120\%. A modo de ejemplo, las cárceles en Suecia presentaban en 2014 el 83\% de ocupación, en Noruega el 97\%, en Finlandia el 98\%, en Alemania el 83\%, en España el 84\% y en Rusia el 94\%. Los países que exceden su capacidad presentan un porcentaje de sobreocupación razonable, como Italia con el 106\%, Francia con el 115\%, Inglaterra y Gales con el 110\% y Ucrania con el 120\% (Dünkel y Bern, 2014).

En el plano europeo, las investigaciones científicas encargadas de analizar las razones del aumento y disminución de la carga de trabajo de los sistemas penitenciarios consideran como factores relevantes el modelo político y económico. De acuerdo con investigaciones de académicos como Tapio Lappi-Seppälä o Michael Cavadino, las sociedades neoliberales poseen mayores tasas de encarcelamiento. A modo de ejemplo, el número de personas privadas de libertad por cada 100.000 habitantes en Estados Unidos es de 766 reclusos; en Rusia, la tasa alcanza las 443 personas. Los investigadores han señalado que esto se explica por la menor inversión en gasto social y el mayor nivel de exclusión social que se presentan en estos países.

Por el contrario, en los países escandinavos que adhieren a un modelo de Estado social benefactor, la tasa es de aproximadamente 60 personas privadas de libertad por cada 100.00o habitantes (Cavadino y Dignan, 2006; Lappi-Seppälä, 2009). Quizás estas conclusiones podrían darnos mayores luces de lo que está ocurriendo en nuestro continente (Sozzo, 2016). En todo caso, como explica Dünkel, las tasas de privados de libertad son resultados de una compleja interacción de factores que se encuentran dentro y fuera del sistema penal y no pueden verse como producto de la suerte o el destino, factores que, al final del día, se manejan por los Gobiernos a su plena voluntad (Dünkel y otros, 2010).

Recapitulando, lo que sí está claro en nuestra región es que los mayores niveles de demanda cuantitativa han contribuido a desmedrar el desempeño cualitativo de casi la gran mayoría de los sistemas carcelarios en América Latina, lo que ha causado una fuerte tensión con los derechos humanos. Sin ir más lejos, la Comisión Interamericana de Derechos Humanos ha observado que los problemas más graves y extendidos de la región son: i) hacinamiento; ii) deficientes condiciones de encierro; iii) altos índices de violencia ${ }^{7}$ y control de las autoridades; iv) empleo de la tortura; v) uso ex-

7. Sobre este aspecto, la Corte Interamericana de Derechos Humanos constata en su informe de 2011 
cesivo de la fuerza por parte de los funcionarios encargados de la seguridad; vi) uso excesivo de la detención preventiva; vii) ausencia de medidas que protejan a los grupos vulnerables; viii) falta de programas laborales y la ausencia de transparencia en los mecanismos de acceso a esos programas; y ix) corrupción y falta de transparencia en la gestión penitenciaria (CIDH, 2011a: 1).

\section{Países condenados y derechos vulnerados}

En los últimos cincuenta años, la Corte ha conocido una serie de casos en los cuales la vulneración de derechos ha recaído en víctimas privadas de libertad. El conocimiento y juzgamiento de estos casos ha permitido al tribunal construir un conjunto de estándares de protección de derechos humanos de los privados de libertad que resultan mandatos decisivos a la hora de fortalecer la defensa de este grupo en las jurisdicciones domésticas (Nash Rojas, 2010: 197).

Es necesario precisar que los casos conocidos por la Corte, y de los cuales se ha desarrollado una línea de estándares en materia carcelaria, han tenido un foco problemático más amplio que el de la ejecución de las sanciones penales. Son casos que contienen diversas temáticas jurídicas, como ejecución extrajudicial, debido proceso, pena de muerte, detención ilegal, principio de legalidad, integridad corporal y masacre, entre otros.

La Corte ha conocido más de 40 casos en que una de las dimensiones de la vulneración de derechos reclamada está vinculada con la lesión de derechos en el interior de una prisión o lugar de detención. Teniendo en cuenta lo anterior, se puede afirmar que los países que más condenas han recibido por vulnerar derechos en el interior de las prisiones son Perú con 12 condenas; Ecuador, Argentina y Venezuela con 5, y Honduras con 4. Otros países como Haití y Trinidad y Tobago han sido condenados en dos ocasiones. Por su parte, México, Brasil, Guatemala, Barbados, Colombia, Paraguay, Bolivia y Surinam han sido condenados en una sola ocasión.

De acuerdo con la Corte, los derechos de la Convención Americana de Derechos Humanos que con mayor frecuencia son vulnerados en el interior de los recintos carcelarios son: el derecho a la vida (artículo 4); el derecho a la integridad corporal (artículo 5); la prohibición de la esclavitud y servidumbre (artículo 6); la libertad de conciencia y de religión (artículo 12); el principio de legalidad y de retroactividad (artículo 9); y el derecho a la protección de la familia (artículo 17) (Andreu, 2013; Antkowiak, 2013; Ayala Corao y Rivero, 2013; Beloff, 2013; CIDH, 2011a; Huaco Palomino, 2013; Nash Rojas, 2013).

que la violencia carcelaria es uno de los problemas más graves en la región. A modo de ejemplo, en Venezuela ocurrieron más de 1.865 muertes y 4.358 heridos en las prisiones entre 2005 y 2009 (CIDH, 2011a: 36). 
Según la Corte, el derecho a la vida de los privados de libertad se vulnera por el uso desproporcionado de la fuerza por parte de las instituciones penitenciarias en el interior de los recintos penales (Ayala Corao y Rivero, 2013: 127). ${ }^{8}$ Con respecto de la integridad corporal, el tribunal americano considera que se lesiona el artículo 5 de la Convención cuando las condiciones en el interior de las prisiones no satisfacen ciertos estándares básicos, como brindar espacios mínimos e iluminados, asegurar la separación por categorías, acceso al agua, alimentación con valor nutritivo suficiente, atención médica regular, visitas, y educación, trabajo y recreación (Medina, 2003: 203; Nash Rojas, 2013: 152).

En la misma línea, la detención en condiciones de hacinamiento; el aislamiento en celda reducida, con falta de ventilación y luz natural; la falta de cama para el reposo y condiciones adecuadas de higiene; la incomunicación o las restricciones indebidas al régimen de visitas; la falta de atención médica; el encierro de migrantes en establecimientos carcelarios y la falta de investigación en casos de denuncias de malos tratos o tortura sufrida por los presos también son, de acuerdo con la Corte, vulneraciones a la integridad corporal. ${ }^{9}$

En lo que dice relación con la prohibición de trabajos forzosos, la Corte lo considera contrario a la Convención en cualquiera de las siguientes hipótesis: i) cuando se aplica a procesados; ii) cuando no está contemplada previamente en la ley; iii) cuando se impone por un tribunal dependiente, parcial e incompetente; o iv) cuando afecta la dignidad, capacidad física e intelectual del condenado (Andreu, 2013: 175).

La libertad de conciencia y religión puede verse afectada con cualquier limitación. En su análisis, la Corte considera que estas libertades no admitirían ningún tipo de afectación y deberían ser efectivamente respetadas y garantizadas como las de cualquier persona no sometida a privación de libertad (Huaco Palomino, 2013: 302).

El derecho a la protección de la familia se vulnera cuando se ordenan traslados a distancias extremas de los familiares y cuando se restringen arbitrariamente las visitas familiares y conyugales. ${ }^{10}$

Los principios de legalidad y retroactividad en el análisis de la Corte se verían lesionados cuando las definiciones del delito y los términos relacionados con la sanción penal no se encuentran contemplados en una ley. El artículo 9 de la Convención

8. Sentencias de los casos Neira Alegría con Perú, 19 de enero de 1995, serie c número 20; y Durand Ugarte con Perú, 16 de agosto de 2000, serie c número 68.

9. Sentencias de los casos Montero Aranguren y otros con Venezuela, 5 de junio de 2006, serie c número 150; Servellón Garcia con Honduras, 21 de septiembre de 2006, serie c número 152; López y Álvarez con Honduras, 1 de febrero de 2006, serie c número 141; Penal Miguel Castro con Perú, 21 de septiembre de 2006, serie c número 160; Instituto de Reeducación del Menor con Paraguay, 2 de septiembre de 2004, serie c número 112.

10. Informe 67/o6, caso 12.476 Oscar Elías Biscet y otros con Cuba, Comisión Interamericana de Derechos Humanos. 
debería ser leído en conjunto con el artículo 30: para el derecho internacional de los derechos humanos, la regulación penitenciaria basada en reglamentos infringe el principio de legalidad, toda vez que las limitaciones de derechos de las personas presas son decididas por autoridades administrativas y no por el Parlamento. En este sentido, el tenor literal del artículo 30 de la Convención no admite dudas: «Las restricciones permitidas $[\ldots]$ al goce y ejercicio de los derechos y libertades $[\ldots]$ no pueden ser aplicadas sino conforme a leyes». A su turno, la Corte Interamericana de Derechos Humanos ha interpretado el concepto ley en sentido formal, esto es, como norma jurídica adoptada por el órgano legislativo y promulgado por el Poder Ejecutivo (Rodríguez, 2013: 717).

\section{Restricciones generales al poder punitivo}

\section{La dignidad humana como límite al monopolio de la fuerza del Estado}

Antes de describir y analizar la jurisprudencia de la Corte en materia de privados de libertad, es necesario destacar un estándar general que impacta directamente en la temática. Me refiero a la dignidad humana como limite al ius puniendi.

El establecimiento de disposiciones de derecho penal efectivas para disuadir la comisión de delitos contra las personas y el diseño e implementación de un sistema dirigido a la prevención, supresión y castigo de las conductas que transgredan las normas penales, son deberes que el Estado debe asumir para asegurar el derecho a la vida y la integridad corporal de la ciudadanía."

Con todo, en el cumplimiento de sus obligaciones en materia de seguridad ciudadana, el Estado no puede valerse de cualquier procedimiento para alcanzar sus objetivos, no puede desarrollar una política criminal sin límites y permitir que los operadores de las distintas instituciones que trabajan dentro del sistema penal lo hagan de forma arbitraria. Como se desprende de los casos Godínez Cruz con Honduras, Durand y Ugarte con Perú y Velásquez Rodríguez con Honduras, ninguna actividad del Estado puede fundarse sobre el desprecio de la dignidad humana.

La Corte también ha sido enfática en materia carcelaria explicando en el caso Montero Aranguren y otros (Retén de Catia) con Venezuela que si bien el Estado tiene la obligación de garantizar la seguridad y mantener el orden público dentro de las cárceles, tiene también el deber de generar condiciones mínimas compatibles con la dignidad humana, adoptar medidas de prevención y crear condiciones para evitar el uso de la fuerza (Nash Rojas y Núñez, 2016).

11. Véanse las sentencias de los casos Velázquez Rodríguez con Honduras, 29 de julio de 1998, serie c número 24; Perozo y otros con Venezuela, 28 de enero de 2009, serie c número 35; y Anzualdo Castro con Perú, 22 de septiembre de 2009, serie c número 15. 


\section{Responsabilidad ante situación especial del privado de libertad}

Es una cuestión aceptada por la Corte que los privados de libertad son un grupo vulnerable, una fragilidad que tiene diversas causas. La primera gira en torno a los efectos que el encierro genera en el penado, esto es, prisionización, desculturación, desidentificación, desmoralización y otros efectos sicológicos como sicosis, neurosis y depresiones (Clemmer, 1958; Goffman, 1992; Liebling y Maruna, 2005). También la vulnerabilidad se explicaría por la total dependencia del penado con la institución penitenciaria. El privado de libertad no puede satisfacer sus necesidades de forma independiente y es sometido a un control permanente, a un régimen de vida con diferentes niveles de rigidez y rutinas que reducen su autonomía (CIDH, 2011a; Goffman, 1992; Nash Rojas, 2010: 197). Se trata, además, de una fragilidad fundada en la escasa visibilidad, que no entregaría iguales niveles de protección de derechos.

Es justamente esta vulnerabilidad la que obligaría al Estado a hacerse cargo del preso y asumir lo que para la Corte sería una verdadera posición de garante, esto es, la obligación de desplegar acciones positivas dirigidas a proteger y garantizar el derecho a la vida y la integridad corporal de los condenados e imputados.

Esta posición de garante compelería al Estado, de acuerdo con los distintos fallos emitidos por la Corte y lo señalado por la doctrina, a cumplir simultáneamente con una obligación de custodia y de protección (Laubenthal, 2015). La primera obligación le exige al Estado desplegar dentro de la prisión medidas que aseguren un orden y seguridad razonable que impida las fugas. Me refiero a lo que Alisch (2001: 10) ha denominado seguridad instrumental (técnicas de vigilancia como alarmas, torres, iluminación y condiciones estructurales de un edificio con sus especificaciones propias, como celdas, ventanas con barrotes y puertas) y seguridad administrativa (reglamentación del recinto, normas de comportamiento de los presos y protocolos internos que contemplan el accionar en situaciones de peligro como incendios, peleas o motines). Detrás de esta obligación, se encuentra el legítimo interés de toda comunidad de que la sanción privativa de libertad sea tomada en serio.

La segunda obligación le exige al Estado comportarse como garante para evitar un resultado que lesiona bienes jurídicos, como dirían Jescheck y Weigend (2002: 668) a propósito de los delitos de omisión, significa «que alguien —en este caso el Estadoestá llamado de un modo especial a la protección del objeto del bien jurídico puesto en peligro, y que todo el resto de la comunidad confía en la intervención activa de ese alguien».

Los deberes de protección relacionados con los derechos a la vida y la integridad corporal poseen para el Estado las siguientes dimensiones dentro de las prisiones (Nash Rojas y Núñez, 2016):

- Asumir una actitud de guardián permanente frente a la población penitenciaria, que se traduce en adoptar mecanismos de resguardo razonables para 
prevenir el peligro de lesión de derechos en el interior de la cárcel. Esto significa que tan pronto tome conocimiento de aquellos riesgos o peligros que se ciernen sobre la población penal, deberá poner en marcha dichos mecanismos de evitación o contención. Por riesgos o peligros dentro de la prisión se entenderían, entre otros, incendios, peleas, enfermedades, suicidios y abusos en el interior de las cárceles, eventos a los cuales el Estado debería estar especialmente atento y dispuesto a prevenir a través de medidas concretas. En cuanto al actuar razonable, deberían contemplarse protocolos de actuación concretos en las correspondientes reglamentaciones.

- Proteger a imputados y condenados por igual, independiente del tipo de recinto penitenciario en que se alojen, sea estatal o administrado por privados. No solo dentro de la cárcel, sino también en los traslados, en la conducción a diligencias judiciales o cuando son llevados a hospitales externos, el Estado tiene la obligación de proteger a condenados e imputados por igual. ${ }^{12}$

- Asegurar dentro de la prisión condiciones mínimas compatibles con la dignidad humana. Lo anterior significa evitar el hacinamiento; asegurar la separación por categorías; brindar acceso al agua potable para consumo e higiene; entregar alimentos de buena calidad y con valor nutritivo suficiente; brindar para todos los privados de libertad educación, trabajo y recreación; garantizar ampliamente las visitas; asegurar que todas las celdas cuenten con luz natural, ventilación e higiene; asegurar limpieza y privacidad en los servicios sanitarios, y entregar revisión médica regular.

- Asegurar una tutela efectiva de los derechos de los reclusos a través de órganos jurisdiccionales, comunitarios y administrativos. ${ }^{13}$

La Corte ha profundizado la idea de vulnerabilidad y ha reconocido que dentro de la cárcel habitan grupos de presos que, por su edad, sexo u otra condición, se encontrarían en una situación de mayor desprotección, lo que exigiría al Estado profundizar o agudizar el deber de cuidarlos que emana de su rol de garante, esto es, brindar a los grupos que tendrían una doble vulnerabilidad dentro de la cárcel mayor atención, cuidados y ayudas particulares. Se trata de grupos como los adolescentes, mujeres, ancianos, diversidades sexuales, etnias indígenas, enfermos y discapacitados que se presentan dentro de la cárcel como minorías y que suelen ser desplazados y discri-

12. La Corte Interamericana de Derechos Humanos extiende el ámbito de protección del deber de cuidado y considera que el Estado debe ser capaz en todo momento de garantizar la seguridad de los reclusos, sus familiares, visitas y personas que trabajan en el interior de la prisión (CIDH, 2011a: 28).

13. Sentencias de los casos Montero Aranguren y otros con Venezuela; Servellón Garcia con Honduras; López y Álvarez con Honduras; Penal Miguel Castro con Perú e Instituto de Reeducación del Menor con Paraguay. 
minados por la institución penitenciaria e incluso objeto de abusos por parte de la población penitenciaria mayoritaria (Castro, Cillero y Mera, 2010: 233).

A modo de ejemplo, en materia de adolescentes (caso Villagrán Morales), la Corte ha establecido que los Estados que violan los derechos de los niños en situación de vulnerabilidad los hacen víctimas de una doble agresión. En el caso Instituto de Reeducación del Menor, señaló que el contacto de los adolescentes privados de libertad con adultos presos expone a los jóvenes a situaciones altamente perjudiciales para su desarrollo y los hace vulnerables ante los adultos, los cuales pueden abusar de su superioridad (Castro, 2016).

Otro grupo dentro de la cárcel que se encuentra en una frágil posición es el de los imputados. Como explica Sergio García Ramírez en su voto razonado del caso Bayarri, los no condenados que están encerrados sufren un alto grado de afectación en sus derechos y desde el punto de vista práctico es difícil advertir la diferencia entre la prisión preventiva y la pena privativa de libertad; incluso, en algunas ocasiones la primera puede llegar a durar mucho más que la segunda (Llobet Rodríguez, 2009).

No cabe duda de que los Estados enfrentan una ardua tarea en materia de resguardo. Como explica la Corte, en dicha labor la coordinación interinstitucional resulta fundamental, ya que confluyen competencias de distintas instituciones del Estado que pasan por los órganos Ejecutivo, Legislativo, entidades administrativas y la judicatura (CIDH, 2011a: 20). ${ }^{14}$ Incluso más, la exigencia de cumplimiento es tal que los Estados no pueden alegar dificultades económicas para justificar el incumplimiento de su rol de garante (Montero Aranguren y otros con Venezuela).

\section{Prohibición de la tortura}

En paralelo a la protección general y de grupos vulnerables dentro de la prisión, la Corte ha desarrollado una serie de estándares y conceptos que giran en torno a la tortura. En este tema es frecuente que la Corte cite la jurisprudencia de la Corte Europea de Derechos Humanos y utilice los estándares de casos como Assenov con Bulgaria, Tyrer con Reino Unido o Irlanda con Reino Unido (Castro, Cillero y Mera, 2010: 126; CIDH, 2011a: 133; Medina, 2003: 150; Nash Rojas, 2013: 143).

La tortura es la conducta que logra el mayor nivel de gravedad. Si bien la Corte no ha desarrollado un listado de acciones que puedan ser consideradas como tortura, ha establecido un conjunto de criterios, como «que sea un acto intencional», «que cause severos sufrimientos físicos o mentales» $\mathrm{y}$ «que se cometa con determinado fin o propósito». ${ }^{15}$

14. Informe sobre la situación de los Derechos Humanos en Ecuador, OEA/Ser. L/V/II.96, doc.10 rev.1, adoptado el 24 de abril de 1997, capítulo 6.

15. Sentencia del caso Bueno Alves con Argentina, 11 de mayo de 2007, serie c número 164. 
En el mismo caso Bueno Alves la Corte explica cada uno de estos criterios. El acto intencional es el desplegado deliberadamente y que no da cabida a la negligencia o al caso fortuito. Respecto de los sufrimientos, toma en consideración, en primer término, el medio utilizado, intensidad con la que se utiliza, duración de la acción ofensiva y los daños físicos y mentales originados en la víctima. En segundo término, la Corte considera «la particularidad de la víctima», como la edad, sexo, estado de salud y cualquier otra circunstancia personal. Y respecto del fin o propósito, la Corte exige que la conducta tenga un thelos, que en el caso en cuestión fue la obtención de la confesión (Nash Rojas, 2013: 143 y ss.; Nash Rojas y Núñez, 2016).

Inmediatamente después en intensidad se encuentran el trato cruel, inhumano y degradante, categorías que no alcanzan el umbral de gravedad de la tortura y que deben evaluarse caso a caso. ${ }^{16} \mathrm{El}$ trato cruel e inhumano tendría una intensidad menor que la de la tortura; a modo de ejemplo, interrogatorios sin lesiones que provoquen turbaciones síquicas. ${ }^{17} \mathrm{El}$ carácter de degradante se configuraría en casos de grave humillación o degradación (CIDH, 2011a: 133).

Destacan como casos de trato cruel, inhumano y degradante la reclusión en aislamiento prolongado, además de cualquier medida que ponga en grave peligro la salud física o mental del recluso, como la detención en hacinamiento; el aislamiento en celda reducida, con falta de ventilación, sin cama ni condiciones de higiene; y la incomunicación o las restricciones indebidas al régimen de visitas. ${ }^{18}$

Otro de los temas que en materia de tortura ha sido desarrollado por el derecho internacional de los derechos humanos y que impacta directamente a los privados de libertad dice relación con la necesidad de una investigación «efectiva», «capaz de llegar a la identificación y al castigo de los responsables», al considerar que sin el deber de investigar, «la prohibición legal general de la tortura y los tratos o penas inhumanos y degradantes, a pesar de su importancia fundamental, sería ineficaz en la práctica y en algunos casos sería posible que los agentes del Estado violasen los derechos que se encuentran bajo su control con virtual impunidad» (CIDH, 2011a: 135). ${ }^{19}$

16. Sentencia del caso Hermanos Gómez Paquiyauri con Perú, 8 de junio de 2004, serie c número 110. 17. Sentencia del caso Villagrán Morales y otros con Guatemala ( Niños de la Calle»), 19 de noviembre de 1999, serie C número 77.

18. Sentencias de los casos Loayza Tamayo con Perú, 17 de septiembre de 1997, serie c número 33; Hilaire, Constantine y Benjamin y otros con Trinidad y Tobago, 21 de junio de 2002, serie c número 94; Suárez Rosero con Ecuador, 12 de noviembre de 1997, serie c número 35; Instituto de Reeducación del menor con Paraguay; Fermín Ramírez con Guatemala; Penal Miguel Castro con Perú; Montero Aranguren con Venezuela.

19. Sentencia del caso Assenov y otros con Bulgaria. Tribunal Europeo de Derechos Humanos, 24760/94 Rep. 1998-8, 28 de octubre de 1998. Véase también la sentencia de Buenos Bueno Alves con Argentina. 


\section{Uso de la fuerza}

El estándar de la Corte en esta materia permite el empleo de armas letales por parte de los cuerpos de seguridad de la prisión cuando sea estrictamente inevitable para proteger una vida y cuando resulten ineficaces medidas menos extremas. ${ }^{20}$ Además, exige que después de que se haya hecho uso de la fuerza, es necesario adoptar medidas para asegurar de forma oportuna y eficaz la asistencia médica. ${ }^{21}$

Para efectos de analizar la proporcionalidad del medio empleado por los agentes de seguridad, la Corte ha evaluado como criterios la ocurrencia de un motín y sus características, el compromiso delictual de los reclusos amotinados, si portaban armas y de qué tipo. En este sentido, la Corte consideró en los casos Neira Alegría y Durand y Ugarte que las características del motín, la peligrosidad de los presos y el uso de armas no constituían elementos suficientes para justificar la utilización de artillería de guerra por parte de los cuerpos de seguridad de la prisión. En el caso Penal Miguel Castro, la Corte concluyó que no existió motín ni otra situación que ameritara el uso legítimo de la fuerza; por el contrario, se trató de un ataque directo para atentar contra la vida de los reclusos.

\section{Límites al ejercicio del poder disciplinario}

En la esfera administrativa, la Corte no solo exige el respeto de las garantías judiciales generales al momento de imponer una sanción disciplinaria (ser oído, juez imparcial, derecho a defensa, plazo razonable, etcétera). ${ }^{22}$ También ha desarrollado estándares especiales para los casos de aislamiento y las requisas.

En el caso Montero Aranguren y otros, concluye que solo puede utilizarse el aislamiento como medida disciplinaria o para la protección de personas por el tiempo estrictamente necesario y bajo los criterios de racionalidad, necesidad y legalidad, en lugares con espacio y ventilación mínimas, y cuando un médico certifique que el preso puede tolerarlas.

En las requisas, la Corte, en su resolución Asunto de las penitenciarías de Mendoza, concluye que el Estado debe permanentemente controlar su periodicidad, su objetivo y que los resultados sean correcta y oportunamente comunicados a las autoridades.

\section{Readaptación de los condenados como finalidad de la pena}

La Corte se ha pronunciado en dos sentidos sobre el complejo tema de los fines de la pena. Si bien el acercamiento no ha sido del todo directo, ha desarrollado algunas

20. Sentencia de Miguel Castro con Perú.

21. Sentencia de Montero Aranguren y otros con Venezuela.

22. Véase sentencia de caso Baena Ricardo y otros con Panamá, Corte Interamericana de Derechos Humanos, 28 de noviembre de 2003, serie c número 104. 
ideas vinculadas con la readaptación de los condenados. En el caso Lori Berenson Mejía señala que las paupérrimas condiciones materiales de un centro privativo de libertad dificultan el cumplimiento de los objetivos de la pena de cárcel. Alerta también a los jueces a la hora de determinar la sanción penal y ejercer el control de ejecución de la pena de atender a las condiciones materiales del encierro.

El segundo análisis que hace la Corte sobre el fin de la pena es el de su duración y la necesidad de que exista después del cumplimiento de la sanción un tiempo suficiente en que el egresado del sistema carcelario pueda desarrollar su proyecto de vida. La idea de que después de la condena exista la posibilidad de desplegar un proyecto de vida se ha vuelto seriamente limitada con las penas de privación de libertad perpetuas. En el caso Mendoza con Argentina se reconoció que el presidio perpetuo impuesto a adolescentes infractores impide la reinserción social, además de infringir la dignidad humana y el principio de proporcionalidad.

De estos dos estándares en torno a la finalidad de la pena podría desprenderse que, para la Corte, la reinserción requiere no solo de una intervención penitenciaria libre de deficiencias y peligros durante el periodo de ejecución o de un ambiente propicio o saludable para la reinserción (Liebling y Arnold, 2004). También exigiría a los Estados asegurar después de la condena un periodo de tiempo para que los egresados tengan la posibilidad de comportarse conforme a la norma penal.

Estos estándares son relevantes en un momento histórico en que el ideal rehabilitador se encuentra debilitado y predomina la idea de la incapacitación, esto es, mantener fuera de circulación por el máximo tiempo posible a los que cometen delitos. No cabe duda de que el énfasis propuesto por la Corte continúa en la línea del artículo 5.6 de la Convención y de la doctrina que le otorga al paso por la cárcel un sentido, el de mejorar la habilidad de los egresados del sistema penitenciario para funcionar en la sociedad con apego a la norma (Van Zyl Smit y Snacken, 2009: 83).

\section{La prisión preventiva}

En los casos Suárez Rosero, Acosta Calderón, López Álvarez, García Asto, Chaparro Álvarez y Bayarri, la Corte ha afirmado que la prisión preventiva debe cumplir una función procesal y no sancionatoria, esto es, la medida cautelar no puede utilizarse como sanción penal e intentar con su aplicación enviar mensajes preventivos generales positivos o lograr la reinserción social del imputado. La prisión preventiva, según la Corte, solo es admisible cuando existe un peligro concreto de fuga o de obstaculización de la investigación.

Lo anterior es interesante porque obliga a descartar causales normalmente utilizadas por los países en sus legislaciones procesales penales, como el peligro de reiteración, la hipótesis de delincuentes habituales o reincidentes, la alarma social o repercusión del hecho para calmar a la ciudadanía, y la selección de determinados 
delitos según la pena aplicable o la gravedad del hecho (Duce y Riego, 2009; Llobet Rodríguez, 2009).

Por otro lado, la Corte expresa que la prisión preventiva se encuentra limitada por el principio de inocencia y proporcionalidad. Así lo ha dicho, entre otros, en los casos Acosta Calderón, Tibi, Instituto de Reeducación del Menor, García Asto y López Álvarez. En el caso Instituto de Reeducación del Menor, recalca la importancia de que la decisión en torno a la aplicación de la medida cautelar debe ser rigurosa; y en los casos Suárez Rosero y Acosta Calderón, establece parámetros que buscan prohibir la prisión preventiva cuando exceda el plazo de lo razonable.

En lo que se refiere a la ejecución de la medida cautelar, el principio de presunción de inocencia exigiría la aplicación de un régimen carcelario más flexible a los imputados, con menores niveles de seguridad y acceso a todo tipo de prestaciones dentro del recinto (Llobet Rodríguez, 2009). También exigiría una separación total con los condenados. En este sentido, la Corte ha mencionado que la infracción del principio de separación implica someter a los imputados a mayores niveles de violencia y que el Estado debe proporcionar a los detenidos revisión médica adecuada y oportuna (caso Tibi con Ecuador) (Nash Rojas, 2013: 154).

\section{Otras formas de reparación}

También resulta interesante, en lo que a privados de libertad se refiere, analizar las «otras formas de reparación» que en conjunto con las indemnizaciones buscan mejorar la posición de las víctimas o sus familiares, enviar mensajes de corte preventivo general y promover la modernización del sistema penitenciario (Nash Rojas, 2004).

La publicación del fallo y el acto solemne de disculpas públicas constituyen medidas para asegurar que el fallo sea conocido por la comunidad del país condenado, y también son útiles para enviar un mensaje dentro y fuera del país respecto de la importancia y vigencia de los derechos humanos. ${ }^{23}$

El tratamiento sicológico o la entrega de becas de estudios son otras medidas que la Corte ha considerado como formas de reparación que buscan brindar un apoyo adicional para las víctimas. También la obligación de investigar o de entregar el cuerpo a sus familiares son medidas reparadoras que apuntan a mejorar aún más la disminuida posición de los lesionados frente al Estado. ${ }^{24}$

\footnotetext{
23. Véase, por ejemplo, las sentencias de los casos Acosta Calderón con Ecuador, 24 de junio de 2005, serie c número 129; De la Cruz Flores con Perú, 18 de noviembre de 2004, serie c número 115; Miguel Castro con Perú; Montero Aranguren y otros con Venezuela; Instituto de Reeducación del Menor con Paraguay; y Fermín Ramírez con Guatemala.

24. Véase, por ejemplo, las sentencias de los casos García Asto Ramírez Rojas con Perú, 25 de noviembre de 2005, serie c número 137; Mendoza y otros con Argentina, 14 de mayo de 2013, serie c número 260; Instituto de Reeducación del Menor con Paraguay; y De la Cruz Flores con Perú.
} 
Capacitar a los funcionarios penitenciarios en el respeto de los derechos humanos, modernizar la ley penitenciaria y mejorar las condiciones de vida en el interior de las prisiones son ejemplos de otras formas de reparación que la Corte ordena a los Estado condenados. ${ }^{25}$

\section{Duración de los procesos}

La crítica al trabajo de los órganos que ejercen jurisdicción en la región -me refiero a la Comsión y la Corte - se ha centrado en la excesiva duración de los procesos, los cuales pueden llegar a durar, entre la ocurrencia de los hechos y el fallo, catorce años. Considérese, por ejemplo, el caso Miguel Castro, que duró 14 años; Neira Alegría duró 11; Mendoza y otros duró 10 y Fermin Ramirez duró 8 años.

El problema radica en que el reconocimiento en torno a la vulneración de derechos y las reparaciones ocurren en su gran mayoría cuando los privados de libertad han egresado del sistema carcelario, lo cual disminuye el significado e impacto de la decisión de la Corte. Por otra parte, la excesiva duración de los procesos viene a poner en dudas el efectivo acceso a las instancias internacionales de protección de los derechos humanos que tendrían los ciudadanos de los Estados partes de la Convención.

\section{Conclusiones}

La prisión preventiva y la cárcel son momentos sensibles dentro del sistema de justicia criminal. El grado de injerencia en la libertad y otros derechos fundamentales, como la vida e integridad corporal, explican la gran importancia de los controles y límites exigidos por la Corte.

La política criminal imperante ha producido un complejo escenario para el funcionamiento de los sistemas penitenciarios, el cual pone en jaque la dignidad humana de los presos. Este escenario ha generado una serie de casos que han sido juzgados por la Corte y que le han permitido construir en el tiempo un conjunto de estándares en materia penitenciaria.

No sería errado afirmar que estos estándares jurisprudenciales fijados por la Corte se han levantado como mínimos que los Estados deben respetar en el interior de sus jurisdicciones y como orientaciones que buscan racionalizar no solo la administración de las prisiones, sino el desconcertante discurso punitivo imperante en la región.

Esta construcción jurisprudencial no ha estado exenta de complicaciones, como

25. Entre otros, Tibi con Ecuador, 7 de septiembre de 2004, serie c número 114; Lori Berenson Mejias con Perú, 25 de noviembre de 2004, serie c número 119; Montero Aranguren y otros con Venezuela; Fermín Ramírez con Guatemala; Hilarie, Constantine, Benjamin y otros con Trinidad y Tobago; y Mendoza y otros con Argentina. 
la de la duración de los procesos y el escaso impacto para generar cambios modernizadores en los sistemas carcelarios de la región -téngase presente al respecto los informes de la comisión sobre el tema carcelario y sobre el sistema penal juvenil de 2011-. Lamentablemente, la legislación ordinaria y la práctica penitenciaria latinoamericana siguen resistiéndose a la modernización, lo que complejiza aún más la realidad carcelaria. Pero esto no impide que continuemos divulgando estos estándares mínimos fijados por la Corte para que, más pronto que tarde, dejen de tener un carácter teórico y puedan plasmarse en la realidad.

\section{Referencias}

AlIsCH, Jörg (2001). «Sicherheit als Steuerungsproblem». En Christoph Flügge, Bernd Maelicke y Harald Preusker (editores), Das Gefängnis als lernende Organization. Baden-Baden: Nomos.

Andreu, Federico (2013). «Artículo 6: Prohibición de la esclavitud y la servidumbre». En Christian Steiner y Patricia Uribe (editores), Convención Americana sobre Derechos Humanos: Comentario. Berlín: Konrad Adenauer Stiftung.

Antrowiak, Thomas (2013). «Artículo 9: Principio de legalidad y retroactividad». En Christian Steiner y Patricia Uribe (editores), Convención Americana sobre Derechos Humanos: Comentario. Berlín: Konrad Adenauer Stiftung.

Ayala Corao, Carlos y María Daniela Rivero (2013). "Artículo 4: Derecho a la vida». En Christian Steiner y Patricia Uribe (editores), Convención Americana sobre Derechos Humanos: Comentario. Berlín: Konrad Adenauer Stiftung.

Beloff, Mary (2013). "Artículo 17: Protección a la familia». En Christian Steiner y Patricia Uribe (editores), Convención Americana sobre Derechos Humanos: Comentario. Berlín: Konrad Adenauer Stiftung.

Castro, Álvaro (2016). Jugendstrafvollzug und Jugendstrafrecht in Chile, Peru und Bolivien unter besonderer Berücksichtigung von nationalen und internationalen Kontrollmechanismen. Mönchengladbach: Vorum Verlag Godesberg.

Castro, Álvaro, Miguel Cillero y Jorge Mera (2010). Derechos fundamentales de los privados de libertad: Guía práctica con los estándares internacionales en la materia. Santiago: Universidad Diego Portales.

Cavadino, Michael y James Dignan (2006). Penal systems: A comparative approach. Londres: Sage.

$\mathrm{CIDH}$, Comisión Interamericana de Derechos Humanos (2011a). Informe sobre los derechos humanos de las personas privadas de libertad en las Américas. Madrid.

-. (2011b). Justicia juvenil y derechos humanos. Luxemburgo.

Clemmer, Donald (1958). The prison community. Nueva York: Holt, Rinehart and Winston.

Cuneo, Silvio (2017). El encarcelamiento masivo. Buenos Aires: Didot. 
DAmmert, Lucía y Patricia Arias (2007). «El desafío de la delincuencia en América Latina: Diagnóstico y respuestas de política». En Lucía Dammert y Liza Zúñiga (editoras), Seguridad y violencia: Desafíos para la ciudadanía. Santiago: Flacso.

Dammert, Lucía y Liza ZúÑiga (2008). La cárcel: Problemas y desafíos para las Américas. Santiago: Flacso.

DucE, Mauricio (2005). Reformas procesales en América Latina: Experiencia de innovación. Santiago: CEJA.

DuCE, Mauricio y Cristián Riego (2009). Prisión preventiva y reforma procesal penal en América Latina: Evaluación y perspectivas. Santiago: CEJA-JSCA.

DÜNKEL, Frieder y Geng BERN (2014). Greifswalder inventar zum Strafvollzug.

Dünkel, Frieder, Tapio LApPI-SeppäLÄ, Kristine Morgenstern y Dirk van ZyL SMIT (2010). «Gefangenenraten und Kriminalpolitik in Europa: Zusammenfassung und Schlussfolgerungen». En Frieder Dünkel, Tapio Lappi-Seppälä, Kristine Morgenstern y Dirk van Zyl Smit (editores), Kriminalität, Kriminalpolitik, strafrechtliche Sanktionspraxis und Gefangenenraten im europäischen Vergleich. Mönchengladbach: Forum Verlag Godesberg.

García-MÉndez, Emilio y Mary Beloff (1998). Infancia, ley y democracia en América Latina. Bogotá: Temis.

GARLAND, David (1990). Castigo y sociedad moderna: Un estudio de teoría social. Buenos Aires: Siglo XXI.

GofFMAn, Erving (1992). Internados: Ensayos sobre la situación social de los enfermos mentales. Trad. de María Oyuela. Buenos Aires: Talleres Gráficos Color Efe.

Gutbrodt, Tobias (2010). Jugendstrafrecht in Kolumbien. Eine rechtshistorische und rechtsvergleichende Untersuchung zum Jugendstrafrecht in Kolumbien, Bolivien, Costa Rica und Bundesrepublik Deutschland unter Berücksichtigung internationaler Menschenrechtsstandards. Mönchengladbach: Forum Verlag Godesberg.

Huaco Palomino, Marco (2013). «Artículo 12: Libertad de conciencia y religión». En Christian Steiner y Patricia Uribe (editores), Convención Americana sobre Derechos Humanos: Comentario. Berlín: Konrad Adenauer Stiftung.

Jescheck, Hans Heinrich y Thomas WeIGEND (2002). Tratado de derecho penal: Parte general. Trad. de Miguel Olmedo Cardenete. Granada: Comares.

Koeppel, Thordis (1999). Kontrolle des Strafvollzuges. Individueller Rechtsschutz und generelle Aufsicht. Ein Rechtsvergleich. Mönchengladbach: Forum Verlag Godesberg.

LANGER, Máximo (2007). Revolución en el proceso penal latinoamericano: Difusión de ideas legales desde la periferia. Santiago: CEJA.

LAPPI-SEPPÄLÄ, Tapio (2009), «Imprisonment and penal policy in Finland». En Peter Wahlgren (editor), Scandinavian studies in law. Volumen 54. Estocolmo: Stockholm Institute for Scandinavian Law.

Laubenthal, Klaus (2015). Strafvollzug. Heidelberg: Springer. 
Liebling, Alison y Helen Arnold (2004). Prisons and their moral performance: A study of values, quality, and prison life. Volumen 19. Oxford: Oxford University Press.

Liebling, Alison y Shadd Maruna (2005). The effects of imprisonment. Devon: Willan.

LLOBET RodRíGUEZ, Javier (2009). «La prisión preventiva y la presunción de inocencia según los órganos de protección de los derechos humanos del sistema interamericano». Revista del Instituto de Ciencias Jurídicas de Puebla, 3 (24): 114-148. Disponible en http://bit.ly/2AsBKjz.

Medina, Cecilia (2003). La Convención americana: Teoría y jurisprudencia. Vida, integridad personal, libertad personal, debido proceso y recurso judicial. Santiago: Universidad de Chile, Centro de Derechos Humanos.

Nash Rojas, Claudio (2004). Las reparaciones ante la Corte Interamericana de Derechos Humanos. Santiago: Universidad de Chile, Centro de Derechos Humanos.

-. (2010). La concepción de derechos fundamentales en Latinoamérica. Ciudad de México: Fontana.

-. (2013). «Artículo 5: Derecho a la integridad corporal». En Christian Steiner y Patricia Uribe (editores), Convención Americana sobre Derechos Humanos: Comentario. Berlín: Konrad Adenauer Stiftung.

Nash Rojas, Claudio y Constanza NúÑEZ (2016). Derechos humanos y proceso penal: Estándares de la jurisprudencia interamericana. Ciudad de México: Ubijus.

PRATT, John (2006). Castigo y civilización: Una lectura crítica sobre las prisiones y los regímenes carcelarios. Barcelona: Gedisa.

Rodríguez, Gabriela (2013). «Artículo 30: Alcance de las restricciones». En Christian Steiner y Patricia Uribe (editores), Convención Americana sobre Derechos Humanos: Comentario. Berlín: Konrad Adenauer Stiftung.

Sozzo, Máximo (2016). «A modo de introducción». En Máximo Sozzo (compilador), Postneoliberalismo y penalidad en América del Sur. Buenos Aires: Clacso.

Steiner, Christian y Patricia Uribe (2013). «Introducción general». En Christian Steiner y Patricia Uribe (editores), Convención Americana sobre Derechos Humanos: Comentario. Berlín: Konrad Adenauer Stiftung.

Van Zyl Smit, Dirk y Sonja Snacken (2009). Principles of European Prison Law and policy: Penology and human rights. Oxford: Oxford University Press.

\section{Sobre el autor}

Álvaro Castro Morales es abogado. Doctor en Derecho por la Ernst-MoritzArndt Universität Greifswald, Alemania. Profesor de la Facultad de Derecho de la Universidad de Chile y director del Centro de Estudios de la Justicia de la misma facultad. Su correo electrónico es acastro@derecho.uchile.cl. 
El Anuario de Derechos Humanos es una publicación anual de referencia y consulta en derechos humanos y materias afines, que busca ser un espacio de discusión, difusión y conocimiento de los temas centrales sobre derechos humanos en sus contextos nacional e internacional, poniendo a la disposición del público de manera gratuita los distintos desarrollos doctrinales, jurisprudenciales y legislativos ocurridos en este campo dentro del período anual cubierto por cada edición.

\author{
DIRECTORA RESPONSABLE \\ Nancy Yáñez Fuenzalida \\ EDITOR DE CONTENIDOS \\ Salvador Millaleo \\ SITIO WEB \\ anuariocdh.uchile.cl \\ CORREO ELECTRÓNICO \\ anuario-cdh@derecho.uchile.cl
}

LICENCIA DE ESTE ARTÍ́CULO

Creative Commons Atribución Compartir Igual 4.0 Internacional

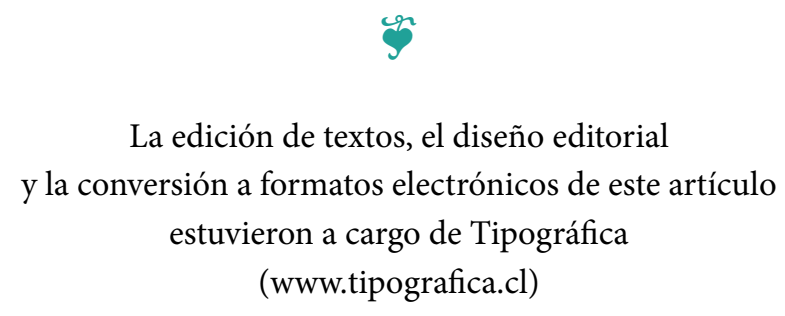

